\title{
An Android Based Game for Children to Learn Fraction
}

\author{
Ika Rahmawati, Shela Dwi Ariyanti \\ Departement of Elementary School Teacher Education \\ Universitas Negeri Surabaya \\ Surabaya, Indonesia \\ ikarahmawati@unesa.ac.id
}

\begin{abstract}
The purpose of this research is to develop an android based game, called Happy Chef game, as a media on mathematics subject materials fraction comparison for four graders of elementary school and also aimed to: (1) Describe the process of developing happy chef game media; (2) Describe the feasibility of the happy chef game media. The background of this research is the material in the student book and learning media did not teach clearly about fraction comparison and the use of mobile phones among children was not appropriate. The method of this research is Development research and uses ADDIE development model. The results of this study are in the excellent category according to the material expert and media expert validator, and get very good grades for student questionnaire assessments and very good categories also for observations. So, it was concluded that the Happy Chef media game is worth to use.
\end{abstract}

Keywords-media; android game; mathematics; fraction comparison

\section{INTRODUCTION}

In millennial era, the development of communication and information technology is growing so rapidly. One product of the development of communication and information technology is a mobile phone or most people call it a handphone. Mobile phones nowadays are familiar, both from children to adults who have and are able to operate them. Mobile is one of the objects that is very easy to carry everywhere and equipped with an internet network and its application makes mobile phones have many benefits for human life in daily activities.

Mobile phone users among children so much and children are very synonymous with the world of education, but it is a pity if the use of mobile phones is not accompanied by maximum use in the world of education. Based on observations by researchers in everyday life that many children have and are able to operate mobile phones. the operation is only used as a pleasure, just as it is used to play games and access social media accounts, even children often forget their time because they are too cool to play. Another example of the results of observations by researchers was that many children bring handphone to school. At school, children are allowed to operate handphone only at certain times, such as when they go home from school and at certain activities that remain under the supervision. When learning, mobile phones are collected in homerooms to be stored so that children do not operate mobile phones during learning. It is unfortunate if the use of mobile phones in children is increasing but its presence has not been utilized as well as possible in the world of education. Therefore, the need for an educator to present positive media to objects that are now close to children, one of which is to use mobile phones as a learning medium for children.

The development of sophisticated technology and information can now be utilized as a medium to develop creativity in creating interesting learning media in the form of audio, visual and motion. Creating interesting learning media by utilizing the development of communication and information technology, one of which is using an Androidbased mobile phone. According to Anggreini [1] Android is a Linux-based operating system that is deployed on mobile devices. Android is excellent because it is open source, making it easier for users to use it. Pitadjeng [2] said that children cannot be separated from the game, so one can develop learning media on an Android-based handphone which is packed with a game, one of which is developing an educational game. Suwarno [3] said that educational games are learning media that are educational and can encourage children to think creatively and be able to play in their learning activities. Anggraini [4] also said that When playing the game, children are able to obtain experience, fun, and also knowledgeWith the development of educational games, children can use mobile phones with positive things because in addition to playing children, they also gain independent learning experience without an educator. Android-based mobile phones are very close to the lives of children, therefore educational games can be used whenever and wherever children are. In addition to developing Android-based educational games, we can participate in utilizing the development of information and technology in the world of education.

Novikasari [5] states that through the results of discussions conducted by a group of elementary / MI teachers, the material in the mathematics lesson that is the most difficult for children to master is fractions. According to Clarke \& Roche [5] based on his research, one of the difficult material in the fraction material is matter comparing fractions. To overcome the problem of difficulties in learning fraction material, of course, as an educator, it must be able to bring up a new innovation by developing an interesting learning media for children to learn 
one of them about material comparing fractions. Considering that children are basically difficult to understand teaching material if it is not presented a learning media because elementary school children whose ages are around 6-12 years are in a concrete operational period, because at that age children are not able to think abstractly so that they need visual media assistance as a tool for Piaget's sequential learning [2].

Subject companion books can also help children in understanding the material, but get facts in Gunanto's book, with the title "Mathematics for SD / MI Class IV", and in the Sugiarto's book with the title "Skilled Mathematics Counting for Elementary / MI Class IV", it has been found that a matter of comparing the denominational numbers mentioned is not the same but is not explained in detail and the sequential way of equating the denominator. In the material immediately stated the statement "equated to 24 " and "equated to 12 " without giving a detailed and coherent explanation of how to equate the denominator. This of course can lead to misconceptions about children's understanding because in the accompanying book the material students are fractions before the GCF (Greatest Common Factors) material which teaches about how to equate the denominator.

In the student companion book Gunanto's book, Desi Andhalia. 2016. Mathematics for SD / MI Class IV. Jakarta: Primary Literature Gelora and in Sugiarto's book, et al there is a QR scan code about comparing fractions but researchers found that the QR scan code does not help fully to learners to learn to compare different denominator denominators because the QR scan code when scanned is still not show in detail how to compare fractions by equating the denominator. Especially in the use of QR scan codes not familiar to students and not all android-based mobile phones can be used to scan QR codes. So that not all students can take advantage of the QR scan code.

Reflecting on these problems, then came the idea to develop an innovative learning media in the form of educational games. By utilizing the development of communication and information technology in the world of education, researchers present an educational game on objects that are close to the lives of children, one of them is an Android-based hand phone. Developing an educational game learning media on Android-based mobile phones to present a learning resource that is not boring because it is packed with audio, visual and motion elements.

\section{METHOD}

The type of research used by researchers is development research or research, which is developing a media based on Android Happy Chef game in the mathematics learning material fractions comparison for fourth grades of elementary school.

The development model used in the development of the Android-based Happy Chef game media is the ADDIE development model developed by Reiser and Molenda in the 1990 s consisting of 5 stages. However, in this study, there were 4 stages which were evaluated in each stage, because in this study formative evaluation was used, namely evaluating each stage [6] which consisted of: analysis stage, design stage, development stage and implementation phase.

The test subjects in the development of the Android-based Happy Chef game media were the fourth grade students of the UNESA (Universitas Negeri Surabaya) Laboratory Elementary School. The selection of the SD Laboratory was used as the subject of the trial because the majority of Elementary School students had a cellphone and were able to operate it and the school allowed its students to bring their mobile phones to school. The location of testing in the development of the Android-based Happy Chef game media is at the UNESA Laboratory Elementary School.

The type of data obtained in the development of the Android-based Happy Chef game media is quantitative and qualitative data. Qualitative data is obtained from the user's opinion regarding the quality of the product being tested. While quantitative data is obtained from material experts, media experts, and users (students). The data was collected using data collection instruments in the form of material validation sheet instruments, media validation sheet instruments, questionnaire sheets and observation sheets. The data analysis techniques from the results of validity using a Likert scale formula.

In this research, researchers used an instrument in the form of a closed questionnaire in the form of rating scale using a Likert scale and an open questionnaire used to obtain input and suggestions given to material experts and media experts.

\section{RESULTS AND DISCUSSION}

The development model used in the development of the Android-based Happy Chef game media is the ADDIE development model developed by Reiser and Molenda in the 1990 s consisting of 5 stages. However, in this study, there were 4 stages which were evaluated in each stage, because in this study formative evaluation was used, namely evaluating each stage [6] which consisted of: analysis stage, design stage, development stage and implementation phase.

First, at the analysis stage, the researcher analyzes students' books, educators, students, literature studies and learning media. Analyzing student books, namely in students' books, mathematics subjects used by UNESA Laboratory School fourth graders, namely the book Exploring Mathematics by Madhavi and Adenoviria [7] have found a material comparing the mentioned fractions is not the same but is not explained in detail to equate the denominator. In the material directly stated the steps multiplying the numerator and denominator by number 4 and multiplying the numerator and denominator by number 3 without being explained in detail where are the two numbers multiplied. This of course can lead to misconceptions about children's understanding because in the accompanying book students the fraction material is taught earlier than the GCF material which teaches about how to equate the denominator.

Next, analyzing the educator is through non-formal interviewing activities, the researcher conducted an interview with the teacher of fourth grade, about mathematical learning materials comparing fractions. Based on the interviews in the 
teacher, it was found that the characteristics of the students in grade IV $\mathrm{C}$ were active learners but some were passive. Learners in the learning process are very happy when their learning is packed with a game, watching videos, telling stories and more. While mathematical learning material compares the fraction of the learning method used by the teacher, the lecture method and the teacher uses the learning medium bread and raffia rope. Bread is used to introduce a variety of fractional values by piece cuts in accordance with the fractions value explained by the teacher, in the use of bread media all learners are involved directly because each participant is asked by the teacher to bring bread from home. While raffia media is provided by teachers used to place various papers containing fractional value comparisons that have been compared to learners to be paired sequentially from the smallest to the largest or vice versa, but in the use of raffia media not all learners are involved in the use of media because teachers use the system to designate learners so that only a few learners get the opportunity to move forward using the media. Next, analyzing the learners through non-formal interview activities, the researchers conducted interviews with some of the fourth grade students on mathematical learning of comparative materials. Based on the results of interviews with some students found that students are still struggling to understand the comparing material fractions, especially comparing denominations are not the same as learners are unaware of the steps in equating the denominator and the learning media presented by teachers are less attractive and tend to be monotonous. In addition, based on the results of observations of researchers there is a fact that many students found to be very enthusiastic in operating mobile phones during school breaks. So the researchers are also interested in conducting non-formal interviews related to the use of mobile phones to some students in fourth grade.

The results of interviews related to the use of mobile phones in fourth grades students, namely: students operate their own Android-based mobile phones during school breaks and at home, students use mobile phones Android based is limited to playing games only and mobile phones that are often operated are Android-based phones. Next analyzing the literature study from the research journal on "Notes on Difficulties in Fractions in Primary Schools / MI in PreLesson Study" conducted by Ifada Novikasari, found in his study that students had difficulty comparing fractions and there were teachers who had difficulty teaching fractions using concrete media or do not know how [5]. And the last one to analyze learning media is from the results of the analysis of learning media can be used as the basis of researchers in designing learning media that will be developed. The results of the analysis of learning media found that the learning media used in mathematics learning material comparing fractions is using bread and raffia. The learning media tends to be monotonous and less helpful for students in understanding mathematics learning material comparing fractions. In addition, the use of raffia learning media only involves a few students. So from the results of the analysis of the learning media, the researchers took the initiative to develop a more interesting learning media by utilizing an Android-based hand phone which was packaged in the form of a game. After carrying out the analysis activities, the researcher conducted an evaluation activity with the help of the supervisor to find solutions from the core problems faced by the students. The results of this evaluation found that there were books on material mathematics students comparing the denominations but there was no detailed method of equating the denominator even though the material comparing the denominations was not the same as the GCF material that taught how to equate the denominator. Of course this will lead to misconceptions towards students, especially many students who still do not understand about how to equate the denominator. In addition, the learning media presented by educators are considered to be less attractive and many students are still having difficulty understanding material comparing fractions. From this, the researchers took the initiative to present a more interesting learning media so that students could be more excited and easier to learn to compare fractions, namely by presenting a learning media by utilizing objects that are now close to children, namely on an Android-based hand phone. Therefore, researchers will develop a Happy Chef based Android game media product to answer these problems.

Second, at the design stage, researchers design learning media by utilizing technological developments by creating an Happy Chef game application that based on Android includes material product design activities and media product design.

When designing material products, the researchers determine the material sub-chapter first, thats about the material sub chapter comparing fractions that are adjusted to first semester IV elementary school book indicators. So, in Happy Chef game that based on Android comparing fractions by equating the first denominator and presented a story problem by relating problem solving in everyday life. Furthermore, researchers designed media products through the process of designing and manufacturing flowcharts to make the flow of orders from the Android-based Happy Chef game media consisting of 3 levels and storyboards to facilitate researchers in producing Android-based Happy Chef game media. After the process of designing and manufacturing media product design and material product design, researchers conducted evaluation activities with the help of a supervisor. Assistance obtained by researchers from the supervisor is in the form of several suggestions that are used as references to improve the design of material products and design of media products. The input given by the supervisor in the material product design is at level 2 to be given 2 examples of problem explanations in the video and questions on level 3 to add questions to 10 questions. In addition, the input given by the supervisor in the design of media products, namely in the design of the flowchart, there are several paths of orders from the Happy Chef game that must be repaired.

Third, the development stage is to realize the design that was made at the design stage to be able to produce an Android-based Happy Chef game media application on the material comparing fractions. In realizing of that design, the tools used to process and develop the Happy Chef based Android media game are: Unity (as a CAI media main processor), Corel Video Studio (as a video processor), Corel Drae X5 and Adobe Photoshop CS6 (as image processing). The materials needed in the Happy Chef based Android media game are : voice recordings for material fillers, sound effect, 
backsound music, background images, pictures related to fractions, images related to the character of happy chef, supporting images as visualisation on the questions that will be presented. After the tools and materials have been prepared, and then entering the next stage is to develop an Androidbased Happy Chef game media. The development stage of the Android-based Happy Chef game media is: 1) Creating a display work window on media with a size of 360 pixels 16:19; 2) Making 2D Unity Project; 3) Incorporating materials that have been made into the project; 4) Make multiple views of the home view and game menu; 5) In the home display there is a media title along with its main character, "Happy Chef", there are a number of menu displays which consist of displaying usage instructions, developer profile display, game display and sound on / off button; 6) In the display of the game menu containing 3 levels, there are on level 1 , comparing the fractions with images, level 2 contains a video along with questions about comparing the denominator by prioritizing the denominator first, and level 3 containing comparing fractions through story problems; 7) Entering the questions that have been made at each level starting from level 1 , level 2 and level 3 with a different set of questions; 8) Make videos that contain material for level 1 and level 2 by using Corel Video Studio; 9) Videos that have been made at level 1 and level 2; 10) Make animations on the Android-based Happy Chef game media from the begin until the end to make it more interesting; 11) Provide backsoundk sound and sound effects with mp3 extensions; 12) Add action scripts on each button to work according to their respective functions; 13) After all the components and program flow are in accordance with the flowchart and storyboard, the project can be published as a media file with an extension (.exe) so that it can run on a computer and laptop and publish it into a media file with extension (.apk) to run on an Android-based handhone. After the Android-based Happy Chef game media has been produced, the Android-based Happy Chef game media is validated by material experts and media experts. Material validation and media validation was carried out by Ika Rahmawati, S.Si., M.Pd. as a lecturer in mathematics as well as a supervisor by researchers in the Elementary School Teacher Education Department, Faculty of Education, State University of Surabaya. Material validation refers to the material validation sheet that has been developed by researchers, there are 13 statements that include learning, material content, presentation, and effectiveness.

From the results, it shows that the material presented in the Android-based Happy Chef game media comparing fractions of mathematics subjects is declared valid without revision (there are some suggestions from the validator) by material experts. Whereas Media Validation refers to the media validation sheet that has been developed by the researchers, there are 14 statements which include the appearance of design, instructions, writing, sound, and convenience.

From the results, it shows that the Happy Chef based Android game media on mathematics subjects comparing fractions was declared valid with mild revisions by media experts.After carrying out the validity test, the researcher conducted an evaluation activity by carrying out revision activities based on some input provided by material experts and media experts. The input given by the material expert, is the writing "flour" is changed to "egg", the writing "less" is changed to "lighter weight", the second video is accelerated from the first video. Next, the input given by the media expert is that the exit button is changed to ( $\mathrm{x}$ ), a system is added to write "user name" so that every time a new player operates the game can begin learning in a coherent manner from level 1 level 3, scrool or used as 2 slides that can be next / back, the object image on level 3 is enlarged, the button "Try again" is changed to "Play again".

Fourth, the implementation phase is to test the Happy Chef Android-based media game product that was held on April 1, 2019 at Unesa Laboratory Elementary School. The subjects of the trial used were students of class IV $\mathrm{C}$ as many as 17 students. The trial process for Android-based Happy Chef game media products is done in a day with 2 hours of study time. In the process of testing Android-based Happy Chef game media products, students operate it on their respective mobile phones. In approximately 1 hour, students are given the freedom to operate the Happy Chef game. The researcher gives freedom to students in operating the Happy Chef game with the aim of knowing whether students can operate and can understand the media of Happy Chef games easily and clearly. During the product trial process, researchers also conducted an observation process of each student in the use of the Androidbased Happy Chef game with the aim of knowing whether students were enthusiastic and understanding in using the Android-based Happy Chef game based on the eyes of researchers. In the process of observation, researchers were assisted by 4 colleagues. At the beginning of the product testing process, students felt very enthusiastic to try to operate the Android-based Happy Chef game because it presented a game on mathematics subjects, especially materials comparing fractions. This can be seen from the results of observations of researchers as well as which when operating the Androidbased Happy Chef game students are very focused in operating it. During the product trial process, there were a number of obstacles, namely there were 5 students not carrying mobile phones but the obstacles could be overcome, namely by borrowing mobile phones by researchers. In addition there are obstacles in the form of confusing students in operating the Android-based Happy Chef game but these obstacles can be overcome by being assisted by researchers. After conducting the product trial process, the researcher gave a questionnaire sheet about the Android-based Happy Chef game to the test subjects to be filled. Questionnaire sheets were given to the trial subjects with the aim that researchers can find out the response and level of user satisfaction when operating the Android-based Happy Chef game so that researchers can find out the level of feasibility of the Androidbased Happy Chef game. Questionnaire sheets about Androidbased Happy Chef games have 15 statements, each statement contains four alternative answers for selected subjects based on their respective judgments. The results of the questionnaire values will be calculated in each item statement using the Percentage Formula for Every Aspect (PSA) first. The background aspect used attracts a total value of 58 and is calculated using the PSA formula then obtains a percentage of 85.2\%; The Animation Aspect used attracts a total value of 59 and is calculated using the PSA formula then obtains a 
percentage of $86.2 \%$; The aspects used clearly get a total value of 61 and are calculated using the PSA formula then get a percentage of $89.7 \%$; The aspect of the instructions for using the Happy Chef game clearly gets a total value of 58 and is calculated using the PSA formula then obtains a percentage of $85.2 \%$; The writing font aspects used in the Happy Chef game obviously get a total value of 57 and are calculated using the PSA formula then get a percentage of $83.8 \%$; The sound aspect of the Happy Chef game clearly gets a total value of 57 and is calculated using the PSA formula then obtains a percentage of $83.8 \%$; The narrator's voice aspect clearly gets a total value of 55 and is calculated using the PSA formula then obtains a percentage of $80.8 \%$; The aspect of using Happy Chef games is easy to get a total value of 58 and is calculated using the PSA formula then get a percentage of $85.2 \%$; The language aspects used are easy to understand, get a total value of 61 and are calculated using the PSA formula, then get a percentage of $89.7 \%$; The aspect of delivering material through images, animations and videos is easily understood to get a total value of 58 and is calculated using the PSA formula then obtaining a percentage of $85.2 \%$; Easy material aspects to understand get a total value of 59 and are calculated using the PSA formula then get a percentage of $86.7 \%$; The learning aspect of mathematics is more fun getting a total value of 61 and calculated using the PSA formula, then obtaining a percentage of $89.7 \%$; The happy aspect of learning with Happy Chef games gets a total value of 62 and is calculated using the PSA formula then obtains a percentage of $91.1 \%$; How good is the Happy Chef game can increase the enthusiasm for learning to get a total value of 64 and calculated using the PSA formula then get a percentage of 94.1\%; The more interested aspect of learning to compare fractions with Happy Chef games is to get a total value of 61 and calculated using the PSA formula then get a percentage of $89.7 \%$, and also shown on the diagram 1 below:

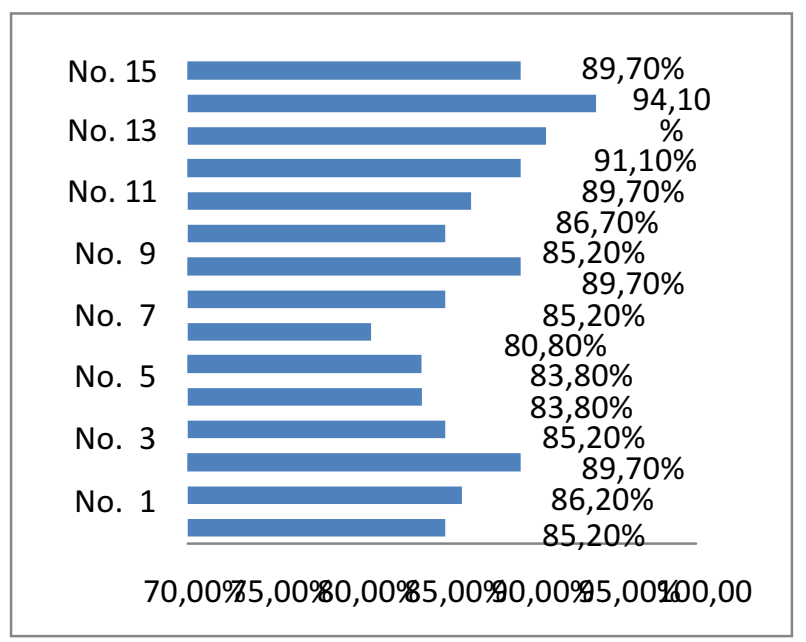

Fig.1. The percentage of Questionnaire Result

From the results of these percentages, it can be said that of all aspects of the observations of the test subjects get a percentage value of $95 \%$ which means that the test subjects in operating the Android-based Happy Chef game are very good. So from the results of the second percentage, it can be said that the media product of Happy Chef based on Android on material mathematics subjects comparing fractions is very feasible to use as a learning medium. The results of the evaluation activities, the results of the questionnaire obtained on the Android-based Happy Chef game media on mathematics subject matter comparing the average fractions of the overall aspects showed that the media of Happy Chef games based on Android on material mathematics compared fractions was very feasible. So that the development of Android-based Happy Chef game media products can be said at this stage as the final product.

Based on the results of product trials that have been carried out on the test subjects at the UNESA Elementary Laboratory, the Android-based Happy Chef game media on material mathematics subjects compare fractions can be said to be feasible as learning media and can help students learn material comparing fractions. Besides that, Happy Chef games can also increase their excitement and enthusiasm in learning mathematics on material comparing fractions. This is evident from the results of observations of researchers on the aspect of showing a happy attitude in using Happy Chef game media that get a percentage of $100 \%$ and aspects increase the learning interest of students who get a percentage of $100 \%$ so that it can be said that students show an enthusiastic attitude and can increase their interest in learning by using Happy Chef game media. In addition, this is in line with the opinion expressed by Dwiyogo [8] that learning media can channel messages, stimulate the mind, arouse enthusiasm and attention of students to carry out learning activities and according to Gagne [9] that learning media can make students excited to do learning activities.

The use of instructional media in addition to stimulating the mind, arousing enthusiasm and attention. Besides learning media can also improve the understanding of learning for students, this is in line with the opinions expressed by Sundjana \& Rivai [10] who say that the presence of learning media in the learning process can attract students to learn and be able to making learning easier to understand by students because learning materials have a clearer meaning.

Considering students sitting in the fourth grade of elementary school are in the concrete operational stage, that is, students have not been able to think abstractly so that they still need the help of objects that are capable of manipulating concrete objects to be used as learning resources [2] and participants are seated in class IV elementary school is at the iconic stage, namely children can learn by using images of concrete objects that are manipulative [2]. So that it developed an Android-based Happy Chef game media with the aim to manipulate concrete objects to resemble their original form and easily learners understand material comparing fractions in mathematics learning. This is evidenced from the results of the questionnaire sheet on the aspect of the image used which clearly obtained a percentage of $89.7 \%$, which means the image used in the Happy Chef game media is clear.

The Android-based Happy Chef game media was developed in the form of an educational game designed to 
make it easier for students to learn material mathematics to compare fractions. In addition, the Android-based Happy Chef game is designed so that students besides playing can also carry out learning activities in it so that children can think creatively [3] and can stimulate thinking power and practice concentration [11]. This is evidenced from the observation sheet on the aspect of paying attention to each explanation in the content of the material which gets a percentage of $88.2 \%$, which means that almost all students pay attention to the explanation in the material through a tutorial and video with focus and concentration. It is also supported by the Encyclopedia of Educational Research [10], saying that the benefits of learning media can increase the attention of students to understand the material in the learning process. Besides that, the Android-based Happy Chef game media is packed with 3 levels which are operated in a coherent manner so that students can learn material comparing fractions continuously, coherently and regularly according to the level of material that must be learned.

\section{CONCLUSION}

Based on the results of research and discussion of the development of Happy Chef game media (Andoid-Based), conclusions can be drawn as follows: 1) Development of Happy Chef game (Android-based) for fourth grades of elementary school using the ADDIE development model, consisting of: First, the analysis phase analyze student books, educators, students, literature studies and learning media; Second, the design stage is designing material products and designing media products in the form of flowcharts and storyboards; Third, the development stage is to realize the design plan in the form of an Android-based Happy Chef game media; Fourth, the implementation phase is to test products to fourth grade students of the UNESA Laboratory. From the four stages, evaluation activities are included in each stage; 2) The Happy Chef game media (Android-Based) for fourth grades of elementary school based on the results of the test subjects' questionnaire getting a percentage rating of $87.1 \%$ and supported by observations getting a percentage rating of $95 \%$. So that the Happy Chef game media (Androidbased) is very feasible to use as learning medium.

\section{REFERENCES}

[1] Chusni, Muhammad Minan, dkk. APPY PIE Untuk Edukasi. Yogyakarta: Media Akademi. 2018.

[2] Pitadjeng. Pembelajaran Matematika yang Menyenangkan. Yogyakarta: Graha Ilmu. 2015.

[3] Suwarno. Game Edukasi. Jakarta: BINUS UNIVERSITY Faculty Of Humanities. 2017. Online), https://pgsd.binus.ac.id/2017/12/31/gameedukasi/ accessed on 20 November 2018.

[4] Novikasari, Ifada. Jurnal Catatan Kesulitan Pecahan di SD/MI dalam Pra-Lesson Study. Purwokerto: IAIN Purwokerto. 2018. (Online), https://www.academia.edu/29993520/Catatan Kesulitan Pecahan di S D MI dalam Pra-Lesson Study accessed on 20 November 2018.

[5] Branch, Robert. Instructioal Design: The ADDIE Aproach. University of Georgia. 2010

[6] Madhavi dan Adenoviria. Jelajah Matematika. Jakarta: Yudhistira. 2018

[7] Dwiyogo, Wasis D. Media Pembelajaran. Malang: Wineka Media. 2013.

[8] Sadiman, Arief. dkk. Media Pendidikan. Jakarta: PT Raja Grafindo Persada. 2012.

[9] Arsyad, A. Media Pembelajaran. Jakarta: PT. Raja Grafindo Persada. 2017.

[10] Handriyantini, Eva. Permainan Edukatif (Educational Games) Berbasis Komputer Untuk Siswa Sekolah Dasar, Volume 01, 2016, Halaman. 130-134. Malang : Sekolah Tinggi Informasi \& Kompuer Indonesia. 2009 (Online), https://www.researchgate.net/publication/284165891 Permainan Eduka tif Educational Games Berbasis_Komputer_untuk_Siswa_Sekolah_Da sar accessed on 18 November 2018.

[11] Anggraini, Kristin. The Influence of Smart Board Game Toward 4-5 years old Childern's Cognitive Development, in Proceedings of 2nd International Conference on Education Innovation, 2018, pp. 104-107. 